

\section{Disclaimer:}

This publication may be reproduced in whole or in part and in any form for educational or non-profit services without special permission from the copyright holder, provided acknowledgement of the source is made. UN Environment would appreciate receiving a copy of any publication that uses this publication as a source. No use of this publication may be made for resale or any other commercial purpose whatsoever without prior permission in writing from UN Environment. Applications for such permission, with a statement of the purpose and extent of the reproduction, should be addressed to the Director, Communication Division, UN Environment, P.O. Box 30552, Nairobi, 00100, Kenya.

The designations employed and the presentation of material in this publication do not imply the expression of any opinion whatsoever on the part of UN Environment concerning the legal status of any country, territory or city or its authorities, or concerning the delimitation of its frontiers or boundaries. For general guidance on matters relating to the use of maps in publications please go to: http://www.un.org/Depts/ Cartographic/english/htmain.htm

Mention of a commercial company or product in this publication does not imply endorsement by UN Environment. The use of information from this publication concerning proprietary products for publicity or advertising is not permitted.

(c) Maps, photos, and illustrations as specified. 


\section{Communicating Ecosystem-Based Management}

\section{Editors}

Maria Potouroglou - GRID-Arendal, John Davis - OCTO

\section{Contributors}

Nicolien Delange, Kanako Hasegawa - UN Environment

\section{Case-studies contributors}

\#1 Abu Dhabi Blue Carbon Demonstration Project: Jane Glavan - Abu Dhabi Global Environmental Data Initiative (AGEDI), Christian Neumann - GRIDArendal

\#2 Marine Plan Partnership (MaPP) for the North Pacific Coast of British Columbia Canada: Charlie Short, Fiona Kilburn, Gord McGee, Steve Diggon \#3 Rare and its Pride Campaigns: Kevin Green, Stephen Box, Emily Laliberte \#4 Coastal Conservation and Education Foundation (CCEF): Alan White, Moonyeen Nida Alava, Michiko Bito-on, Lloyd Genon Yosoya, AJ Lozada \#5 Partnerships in Environmental Management for the Seas of East Asia (PEMSEA): Ryan Whisnant, Adi Cayaban

\section{PCI Media and partners "Punta Fuego" radio program}

Sean Southey, Carina Schmid, Alleyne Regis, Graciela Leal, Ralna Lewis, Loretta Cheung, Richard Crompton 


\section{Contents}
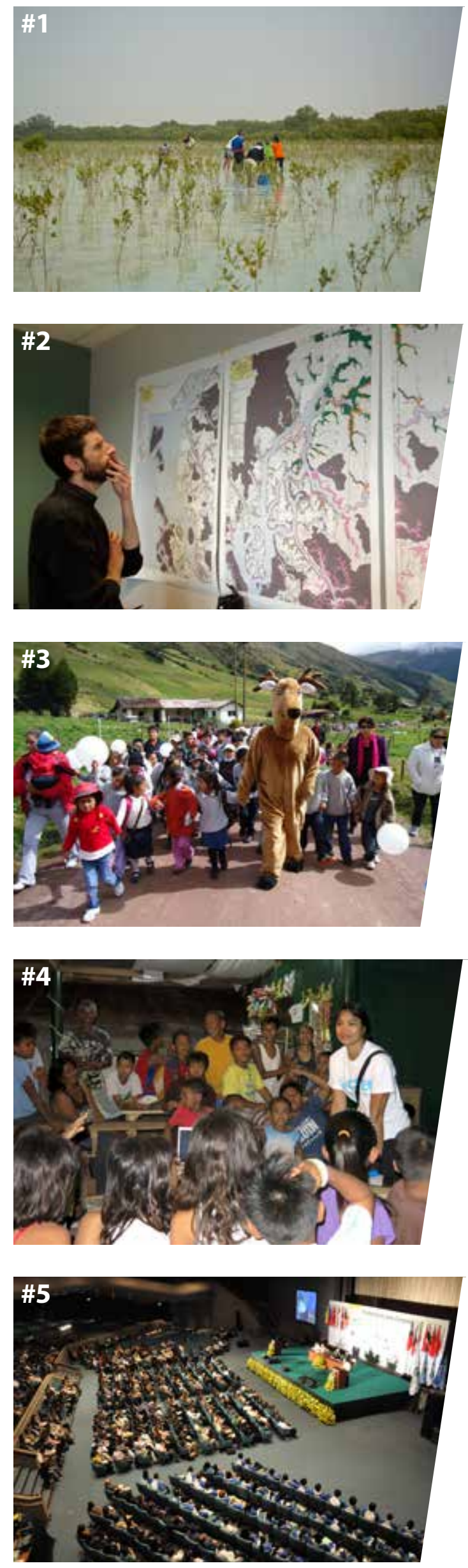

5 Key messages

6 Setting the stage

\section{Case studies}

8 \#1 Abu Dhabi Blue Carbon Demonstration Project

10 \#2 Marine Plan Partnership (MaPP) for the North Pacific Coast of British Columbia, Canada

12 \#3 Rare and its Pride Campaigns

14 \#4 Coastal Conservation and Education Foundation (CCEF), the Philippines

16 \#5 Partnerships in Environmental Management for the Seas of East Asia (PEMSEA)

18 Thinking out of the box: Punta Fuego

19 Sharing is caring: lessons learned from the case studies

21 Applying best practices to your practice: five things to adopt

22 Reference material

23 Photo credits 


\section{Key messages}

\section{Acknowledging connections is central to ecosystem-based management}

Ecosystem-based management focuses on the array of services that ecosystems provide, the effects of human activities on them, and the importance of working towards common goals across multiple and diverse sectors.

\section{Ecosystem-based management and communications should both be holistic}

Sharing knowledge and best practices, and learning and adapting management on the ground, are fundamental elements of ecosystem-based approaches. Sound and targeted communications should embrace all available channels and means of communication, including: representation on committees, one-on-one meetings with key influencers, round-table discussions, events, dedicated pages on websites and social media presence, among others.

\section{Stop, listen and align}

Embracing the multi-stakeholder and multidisciplinary nature of ecosystem-based management is key to successful communication. Communication, knowledge-sharing and management, and collaboration can be challenging for a diverse group, but they can also foster creativity and innovation. Considerable time should be spent discovering ways to create shared values, set trends and ensure that your strategy aligns with your stakeholders' interests, positions and needs.

\section{Remember the classical communication model}

The classical communication model has six components: sender, message, channel, audience, effect and feedback. Choose your senders strategically, identify and plan advocacy opportunities, and opt for appropriate communication channels and formats. Create persuasive messages, conduct careful audience segmentation and use visuals that will support and strengthen your messages.

\section{Follow the messages framework and the art of storytelling}

Communicating evidence in an understandable and practical way can increase an audience's engagement and willingness to act upon the knowledge. Whether your goal is to educate, build optimism, inspire or instil curiosity, you will have more impact if you elicit emotion and create a lasting memory. Storytelling has the potential to generate a shared understanding about a situation, topic or problem, and can engage an audience, attract and sustain their interest and enable them to make meaningful connections.

\section{Learn by doing and evolve with the times}

Try new approaches, see what works and adapt to changing conditions. Work with your communication and marketing teams to develop the appropriate tools to track your audience's mood, whether positive or negative. Successes and failures should be shared and captured in project reports, as well as newsletters and annual reports. It is important to be honest about the good and the bad, as your stakeholders will appreciate this openness and transparency.

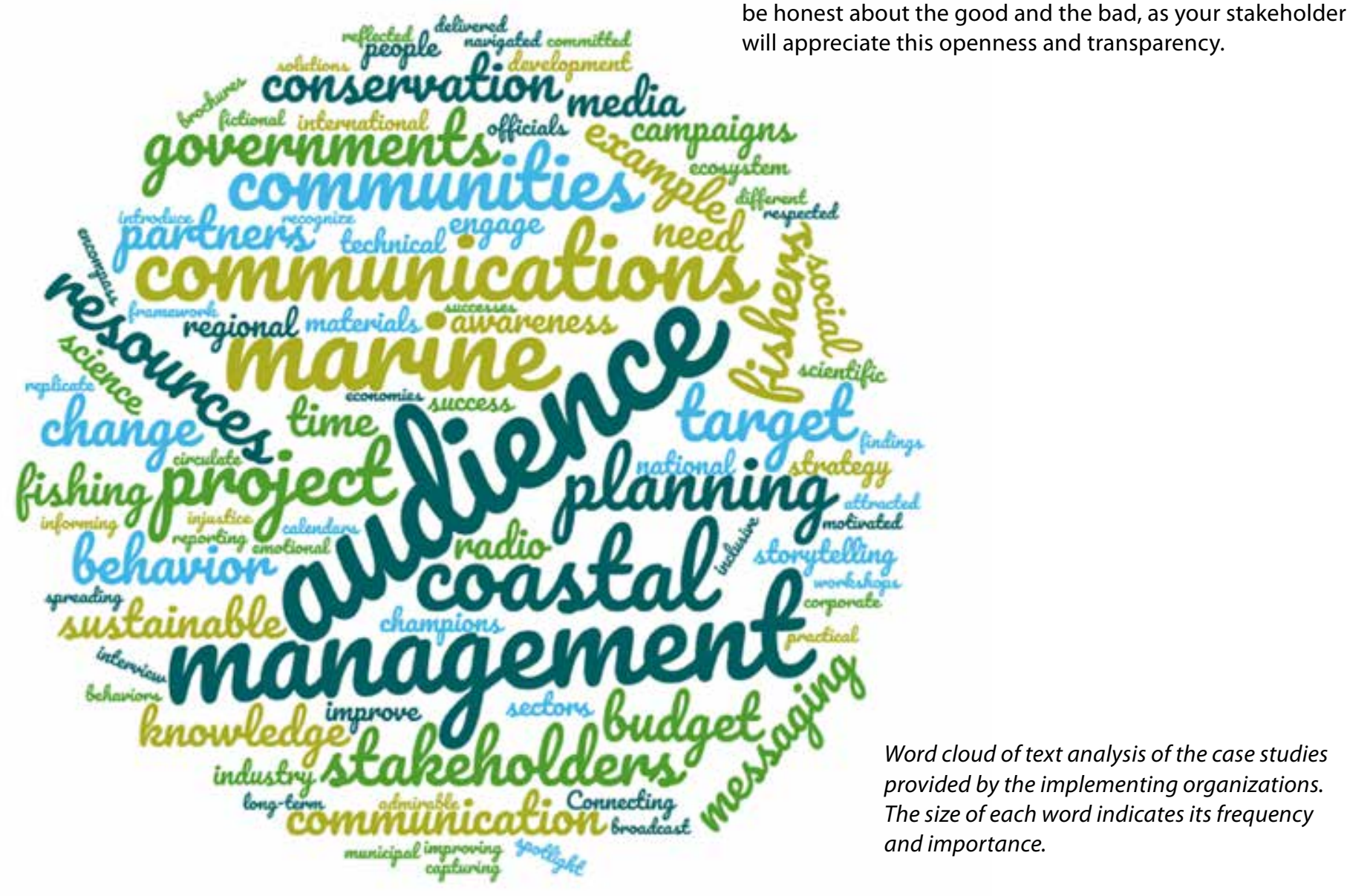




\title{
Setting the stage
}

\author{
"Ecosystem-based management, or EBM, is an approach \\ that goes beyond examining single issues, species, or \\ ecosystem functions in isolation. Instead it recognizes \\ ecological systems for what they are: a rich mix of elements \\ that interact with each other in important ways."
}

(UNEP, 2011)

\section{We are all in the same boat}

Ecosystem-based management emerged in the 1980s, as an alternative to traditional resource management approaches that focused on limited species or had narrow political boundaries. Since then, ecosystem-based management has grown at a rapid pace, requiring the practices of science, communication and management to work together. It does not replace the existing strategies and methods, but it emphasizes the links between the environment and society.

Ecosystem-based management means engaging a broad range of people and organizations that have a stake in how an ecosystem is being managed, from the private and public sectors, to conservation communities, scientists and the policymaking arena. Stakeholders are involved throughout the planning stages, decision-making process and final management decisions. This is often challenging because each stakeholder group might operate by and respond to different mandates, timescales and authorities. The approach therefore requires cross-sectoral coordination and the integration of multi-and intersectoral concerns, in order to build institutional linkages, thereby avoiding conflicts or overlaps.

\section{Ecosystem-based management starts with communication}

Early and consistent engagement of all types of groups helps break down sectoral barriers, facilitates trust and informationsharing, and allows for a broad understanding and vision of the ecosystem being managed. Each organization's role and responsibilities must be agreed upon and made transparent at the start of the process. Ideally this is done by developing a framework for collaboration and communication.

Communication, originating from the Latin word communis meaning "common", should be the glue that binds all ecosystem-based management stakeholders and processes. This report contains information on good practices, as well as providing some guidelines on how to design a communication plan that is tailored to your project by considering the following aspects: developing your communication strategy, connecting with your audience, resources and timescales, measuring success and lessons learned.

Using five case studies, this report strives to highlight practical examples in the communication of ecosystembased management. These case studies were chosen to reflect the diversity of communication objectives and approaches, which could be dependent on factors such as the scale of implementation, geography, entry point, target audience, messages and budget. The parties involved in the case studies share the lessons learned directly from their experience communicating ecosystem-based management projects, describing the challenges they faced and their recommendations for overcoming them, based both on what they did and what they wish they had done. The goal of this report is to share these lessons learned in a manner that is specific enough to explain their genesis, but general enough to be broadly applicable to other projects. It is important to note that these examples are only a small sample of the numerous projects and communication strategies being developed in the field. 


\section{Case studies}

\#1 Abu Dhabi Blue Carbon Demonstration Project

Local scale, Regional Organization for the Protection of the Marine Environment (ROPME) sea region, strategic planning, low-medium budget

\#2 Marine Plan Partnership (MaPP) for the North Pacific Coast of British Columbia, Canada Regional scale, all residents, strategic planning, large budget

\#3 Rare and its Pride Campaigns

Creative "Entertainment-Education"

\#4 Coastal Conservation and Education Foundation (CCEF), the Philippines Local scale

\#5 Partnerships in Environmental Management for the Seas of East Asia (PEMSEA)

Regional scale
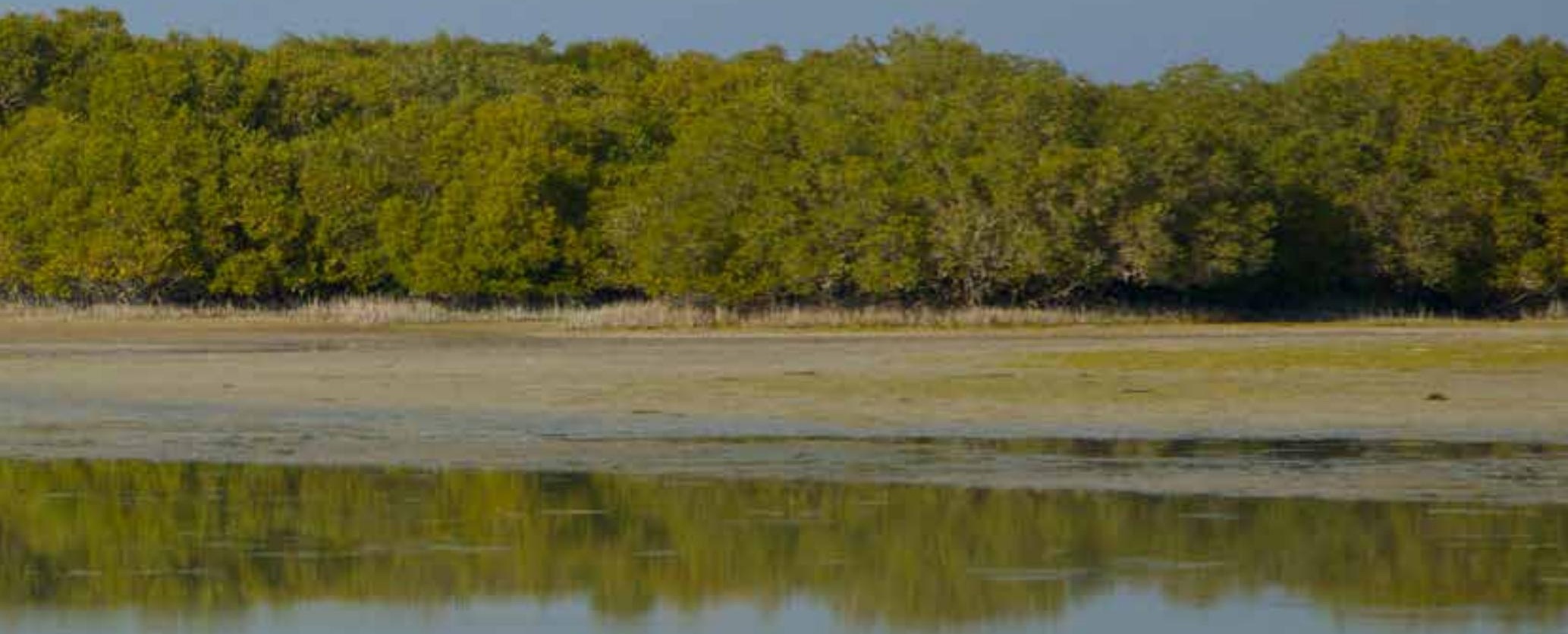


\section{CASE STUDY \\ Abu Dhabi Blue Carbon Demonstration Project}

https://url.grida.no/EBMCase1

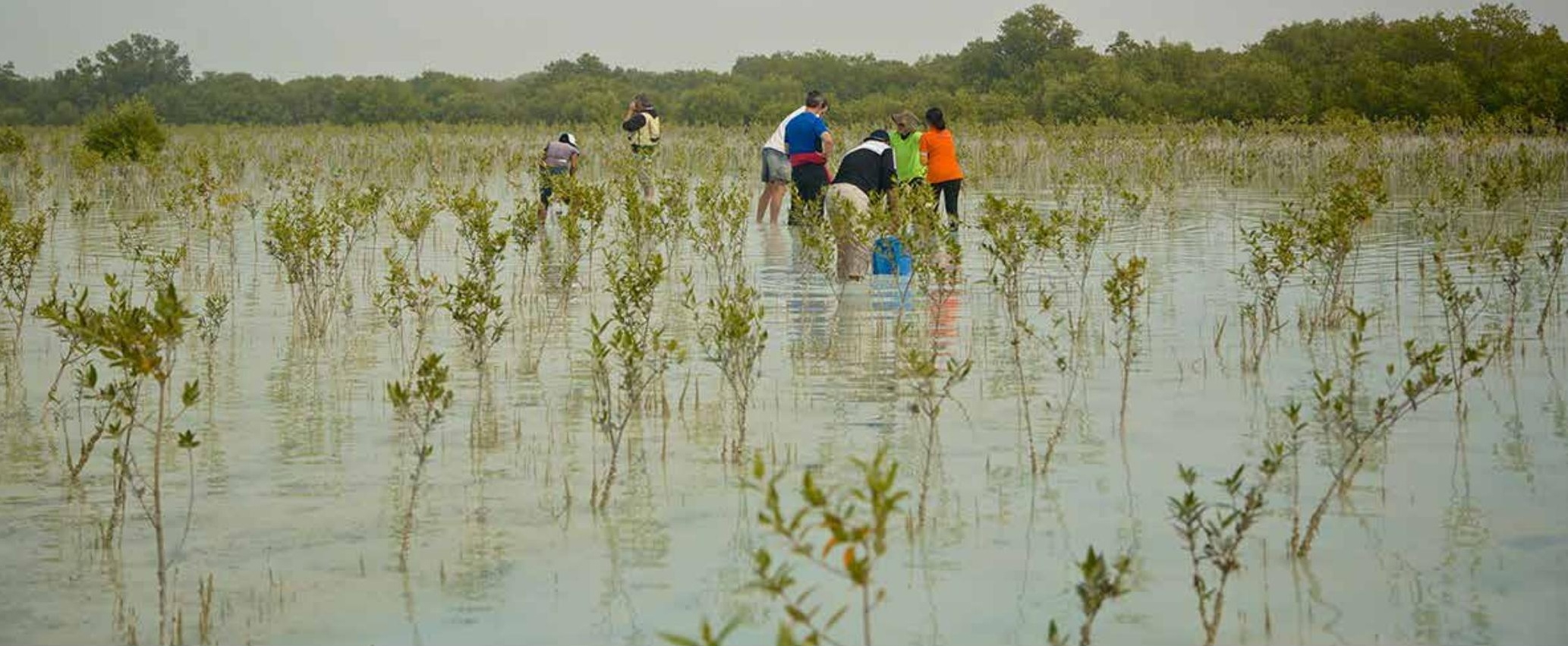

\section{Background}

Blue carbon is the term for carbon stored and sequestered in coastal ecosystems. When healthy, such ecosystems can hold vast carbon reservoirs in their biomass and soil, making their conservation an important step in mitigating climate change.

\section{Communication strategy}

Primary audiences: Government officials and the scientific community

Location: Abu Dhabi and wider UAE

Objective: To raise awareness of blue carbon as a credible and sustainable option that should be protected in national management strategies.

Message: By blending science and local knowledge, new ecosystem concepts can be successfully implemented in policies.

The Abu Dhabi Blue Carbon Demonstration Project - a 2013-2014 partnership between the Abu Dhabi Global Environmental Data Initiative (AGEDI) and GRID-Arendal assessed the blue carbon services and values of Abu Dhabi's coastal ecosystems, including its mangroves, seagrasses, saltmarshes, algal mats and sabkha (salt flats). The project also sought to raise awareness in Abu Dhabi that blue carbon is a sustainable way to integrate carbon into resource management and national strategies for climate adaptation. To do so, the project created a comprehensive communication plan, which also aimed to inspire further conservation action for these blue forests.

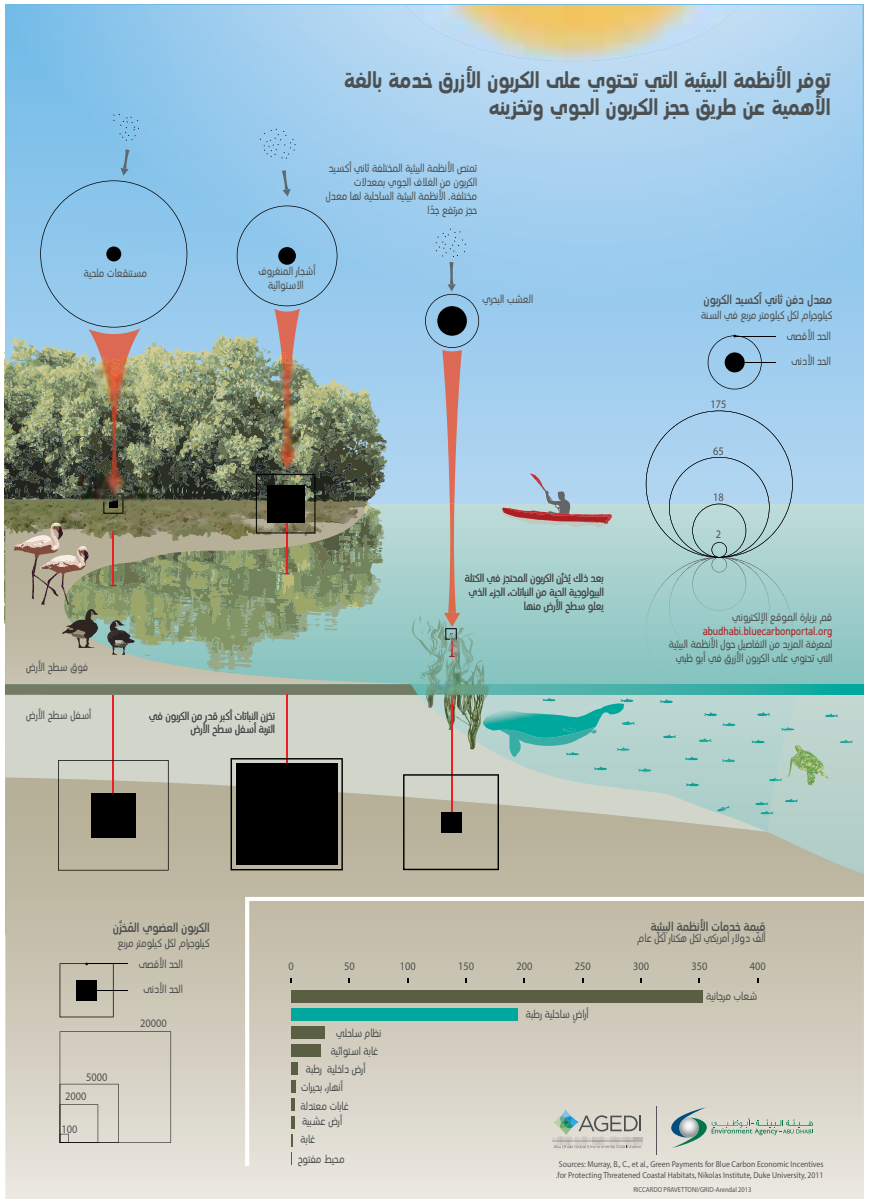




\section{Connecting with the audience}

The plan did not seek an overall attitude change, but rather to amplify the existing conservationist mindset in the UAE, which had been fostered by the nation's first President, the late Sheikh Zayed Al Nahyan, who had instituted extensive mangrove restoration projects. Through the AGEDI/ GRID-Arendal partnership, the project drew on scientific expertise from external blue carbon experts and localized the messaging for several target audiences. Video interviews showcased volunteers and local residents. The messaging reflected on mangroves as part of the UAE's culture and heritage, and the material was communicated to an audience that was already aware of the importance of mangroves but not their role in carbon mitigation.

The Secretary General of the Environment Agency - Abu Dhabi (EAD, which AGEDI is part of) also maintained the same messaging in her speeches and her video interview, thus ensuring consistency in front of locally relevant and wellrespected figures. Project staff identified individual contacts usually advocates within the ministry and the urban planning council, key people in non-governmental organizations (NGOs), as well as esteemed researchers - to help reach even further audiences. This group of experts participated at numerous international conferences, representing the region and presenting the project and its main outcomes.

The communication plan categorized target audiences by three priority levels, from primary to tertiary. The primary level included government and other high-level Abu Dhabi and UAE officials, the scientific community, the higher-level education sector and EAD staff. The plan then assigned objectives for communicating to each of the three audiences, including which materials to share. Some materials were intended to expand their audience's messaging and others to support their policy incorporation. For example, the objective in communicating to scientists was to empower them to continue blue carbon research beyond the project end. The project therefore produced editorials to spotlight participating local scientists in local and international media, and created an online geographic data tool to enable scientists to upload, store and access blue carbon field data.

As the most important audience was government officials, who are key to integrating blue carbon in policies, the project focused on their technical advisers. They received presentation templates and other information to enable and empower them to present blue carbon in ways consistent with the project goals. Publications and online tools were also disseminated to the target audiences via the following websites: http://www.grida.no/publications/181; http://bluecarbonportal.org/abu-dhabi-blue-carbondemonstration-project/ and https://agedi.org/item/abudhabi-blue-carbon-demonstration-project/ as well as on various social media accounts. The websites were mentioned in workshops and meetings, while the social media accounts reached specific followers.

\section{Resources and timescales}

The budget for the entire Blue Carbon Demonstration Project was AED 9 million (USD 2.45 million), with a communications component of AED 783,000 (USD 213,000) - 9 per cent of the project budget. AGEDI's project team included a communications expert with expertise on how to engage Abu Dhabi's audiences effectively. This involved tracking audience input - for example, suggestions on improving the project were collected at public meetings - and informing individuals how and when their comments were integrated. The project was extended from 11 to 15 months, to allow time for more extensive outreach, and required people with design and media production skills to work on its 28 forms of communication materials. Among the less conventional materials were edible postcards advertising blue carbon, which were distributed during the Eid Al Hadha and Eid Al Fitr holidays.

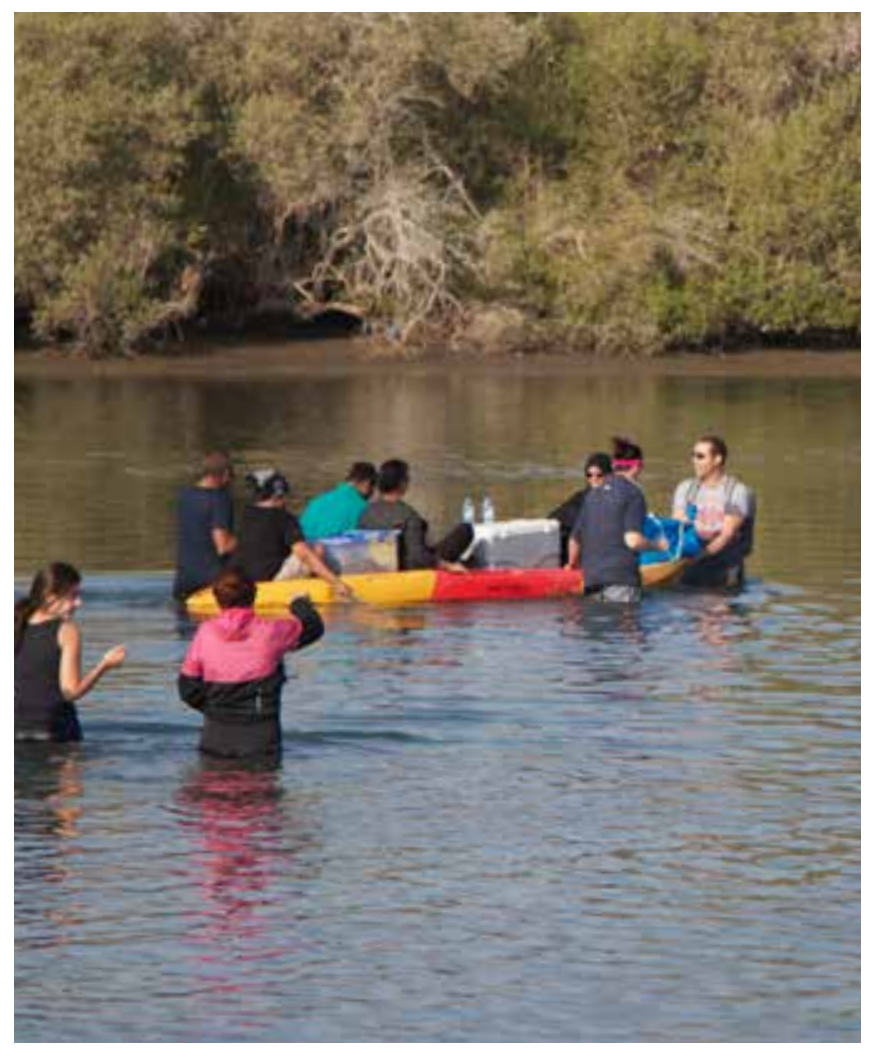

\section{Measuring success}

The project collected few quantitative analytics, aside from tracking newspaper coverage. For example, the guidance document got over 3,400 hits. There is, however, a significant qualitative indicator of success. The project started from very little knowledge of blue carbon science and storage, which was then discussed by others outside the project team, as well as included into numerous planning documents and reporting documents. More specifically, since project completion, blue carbon has been integrated into several Abu Dhabi and UAE policies. These include maritime spatial planning for Abu Dhabi, and the UAE's National Climate Change Plan, Green Growth Strategy, Nationally Determined Contribution and more. Furthermore, Abu Dhabi won the bid for the Ecocity World Summit in 2015, because of its blue carbon work. 


\section{CASE STUDY \#21 Marine Plan Partnership (MaPP) British Columbia, Canada}

https://url.grida.no/EBMCase2
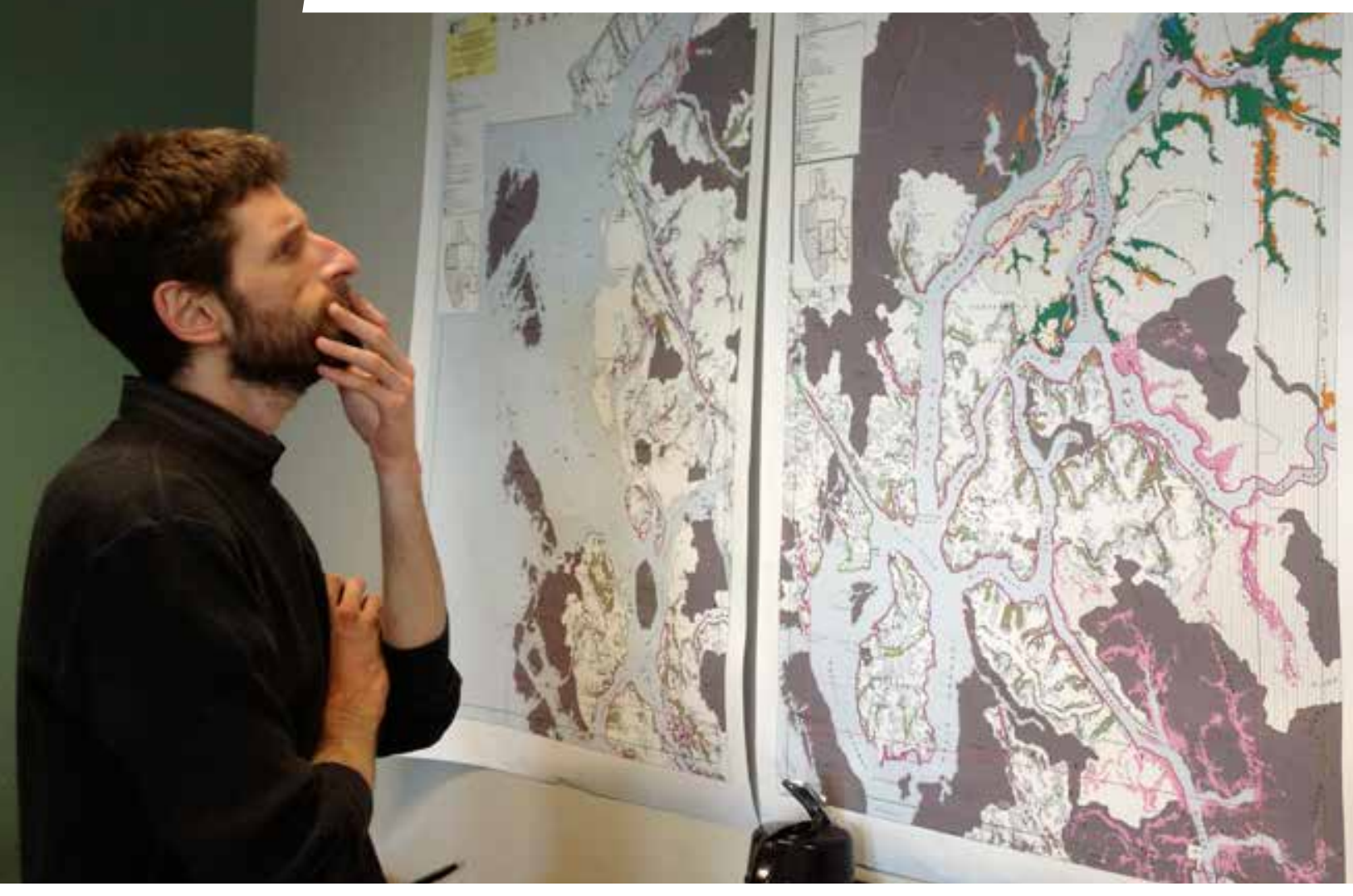

\section{Background}

Off the coast of the western Canadian province of British Columbia (BC), a partnership between the BC government and 17 indigenous First Nations governments has transformed the region's ocean management. The Marine Plan Partnership (MaPP) for the North Pacific Coast applies ecosystem-based management principles that cut across agencies and sectors, rather than taking a traditional sectoral approach. In addition, the co-leaders have incorporated other stakeholders, such as those from industry sectors, local government and conservation. This shift to co-management reflects similar changes in $\mathrm{BC}$ land management, and greater collaboration in general between the $\mathrm{BC}$ government and First Nations governments.

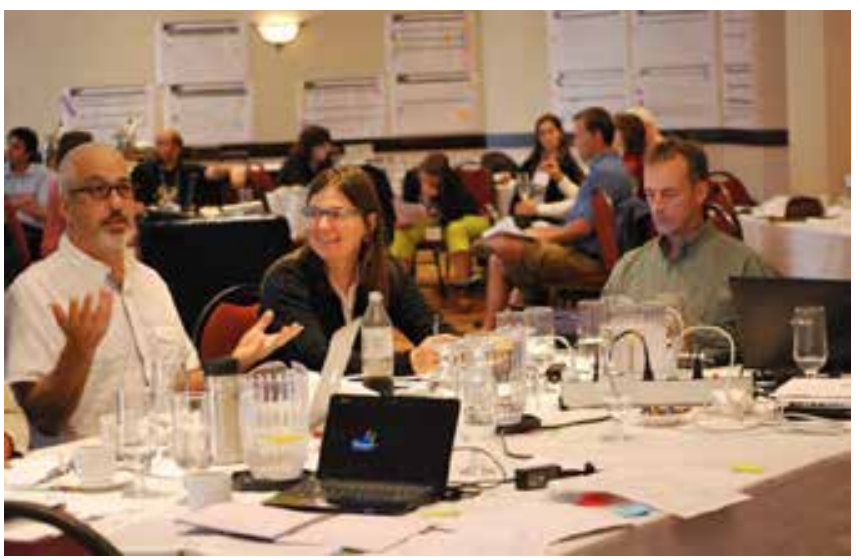

\section{Communication strategy}

Primary audiences: Local governments, industry sectors and the general public

Location: Pacific waters of Canada, also known as the Northern Shelf Bioregion

Objective: To develop and implement ecosystem-based marine plans for the waters of British Columbia.

Message: The best available scientific data supported by traditional and local knowledge can inform plan development and the location, extent and type of spatial zoning.

MaPP started developing a set of marine plans in 2011 to inform regional decisions on stewardship and sustainable economic development. In 2015, the partnership completed four subregional plans, followed by a regional action framework in 2016, which are all now being implemented. MaPP brought significant changes, including the involvement of industry stakeholders who at that time were not on an equal footing with First Nations. Navigating these changes effectively required extensive participation and input from local governments and industry sectors, including forestry, fishing, conservation and tourism. To reach these target audiences, a strategy for communications and outreach was built into MaPP from the outset. 


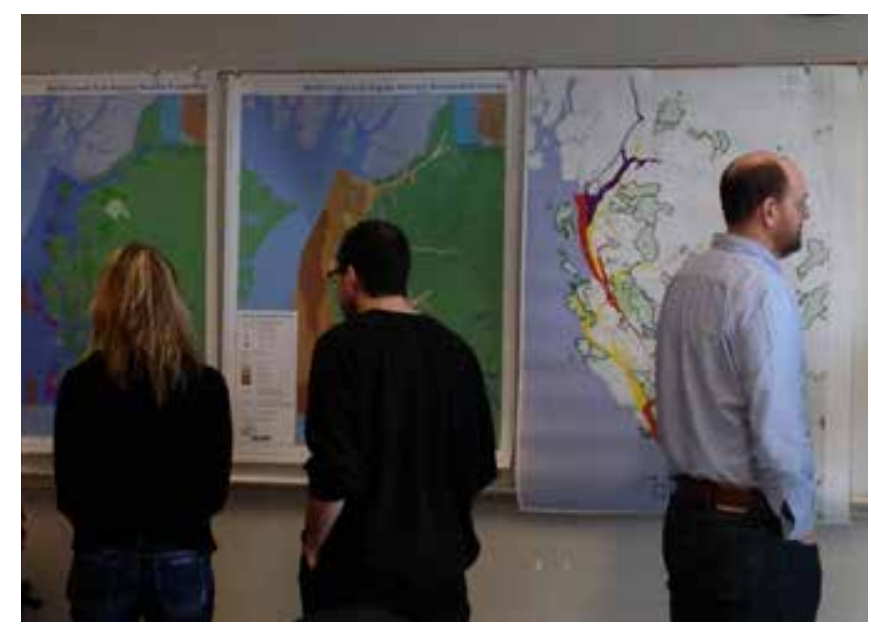

\section{Connecting with the audience}

The strategy had two parts:

1. Communications to explain the need for ecosystem-based management, marine planning and MaPP as a whole. MaPP's project newsletters applied a storytelling approach, featuring real local marine stakeholders to personalize ecosystembased management concepts. In addition, a two-minute video entitled "10 Things You Need To Know About MaPP" was produced and posted on the MaPP website to introduce the project and its purpose. An online portal let stakeholders engage with the project's spatial planning tool, SeaSketch. Also, government agencies received regular formal briefings.

2. In-person outreach to stakeholder groups. Each subregion and the MaPP region overall had a stakeholder advisory committee comprising representatives from local marine sectors and government. Planners held two-day meetings with these committees to receive feedback on planning products. Ten meetings were held per plan area.

Later in the process, MaPP held public 'open houses' to solicit broader community feedback. These were informal, with small tables arranged with maps and a planner at each, ready to answer questions. Attendees could circulate freely and no plans were 'baked in': the goal was to get feedback to inform better planning.

\section{Resources and timescales}

The budget for the entire planning phase of MaPP was CAD 8 million (USD 6.2 million). The CAD 400,000 budget for the communication and outreach components was provided by the Gordon and Betty Moore Foundation. The MaPP team hired consultants to facilitate the meetings and advise planners on stakeholder perceptions. The project also had a staff position for a communications expert to manage storytelling and update the website, among other responsibilities. Communications products required approval by all participating governments (BC and the 17 First Nations), slowing the rollout of new communications products. For example, newsletter distribution was changed from quarterly to twice-yearly.

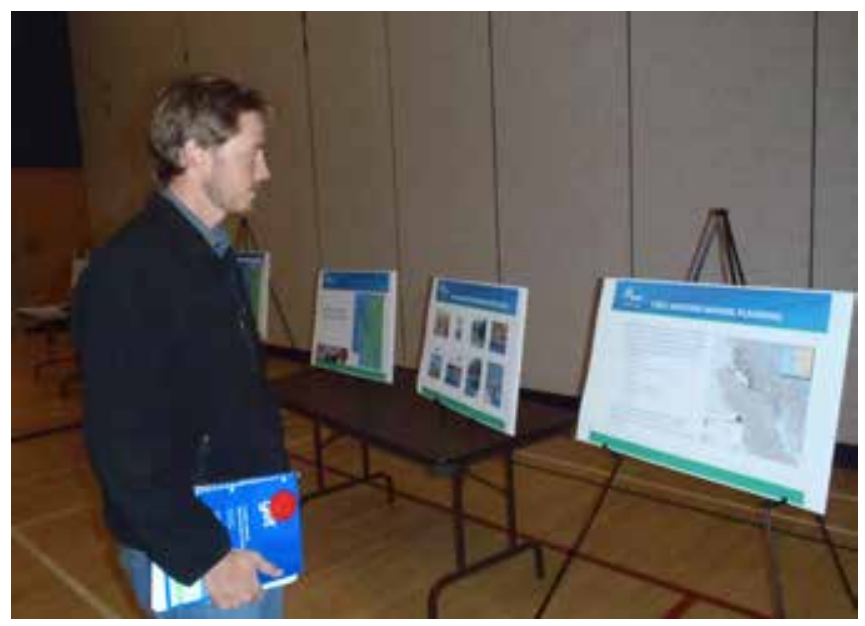

\section{Measuring success}

MaPP hired a consultant to conduct a mid-process and final review of the planning phase. The first review was carried out through conversational interviews with partners (internal) and stakeholders (external) based on a set of base questions developed by the partners and the evaluator. The review's finding that the project needed to improve its communication of ecosystem-based management concepts coincided with a period in which the communications position was temporarily unfilled. In response, MaPP prioritized filling it and established the storytelling approach, which was meant to demystify marine spatial planning for target audiences, and reflect the benefits of the MaPP initiative to partners, stakeholders and the general public.

The project tracked website analytics, comments received, event attendance, and news and social media mentions. The primary measurement of MaPP's success was qualitative, with the planning phase producing a set of marine plans that was approved by all participating governments, marking a new era for marine planning, ecosystem-based management and co-governance in the region.

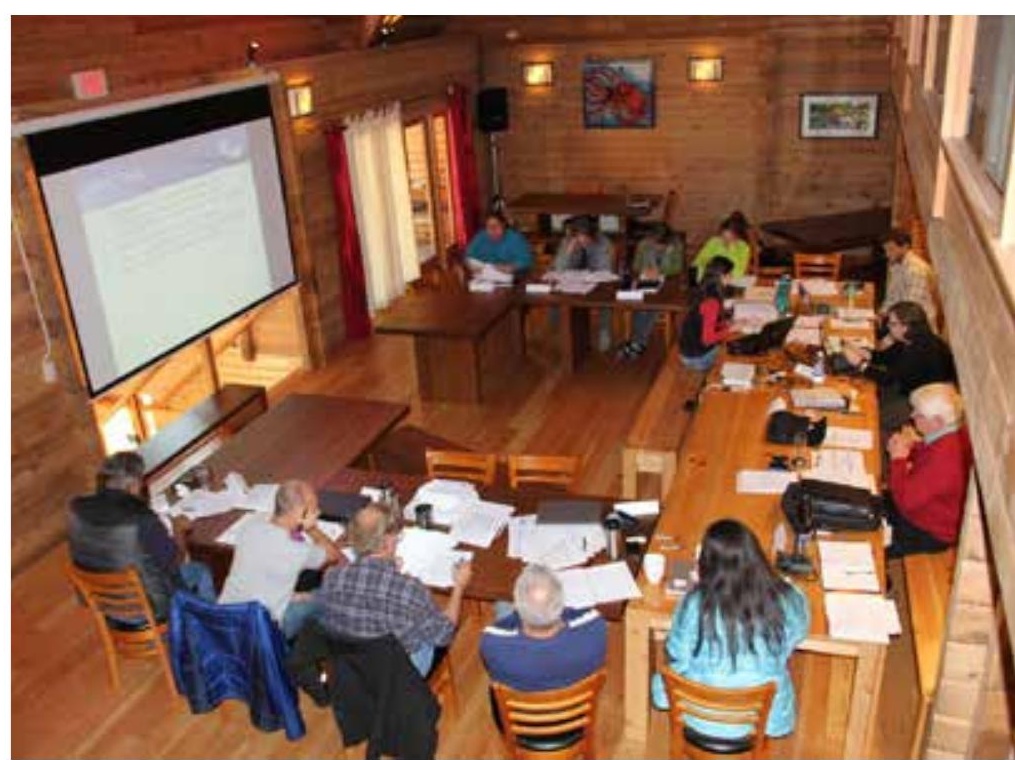




\section{\#3 $1 \begin{aligned} & \text { Rare and its } \\ & \text { Pride Campaigns }\end{aligned}$}

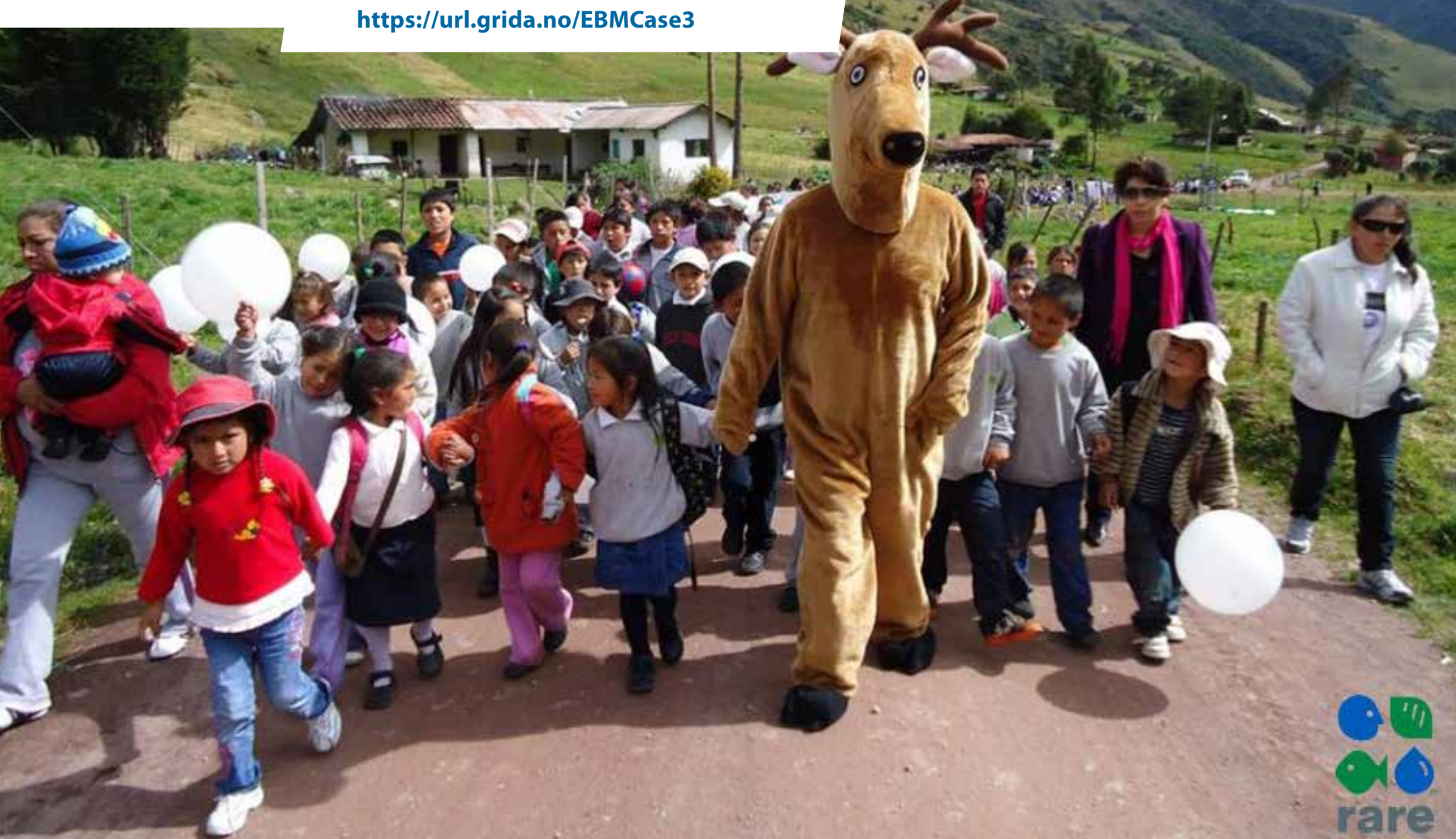

\section{Background}

Rare is an international behaviour change organization involved in conservation. With a particular focus on the sustainability of small-scale fisheries, watersheds and organic agriculture, Rare applies state-of-the-art behavioural science to its conservation projects, believing that almost all challenges in resource management require human behaviour change. To prompt individuals to adopt a more sustainable behaviour, they must be motivated and influenced through a combination of emotional, normative and contextual approaches.

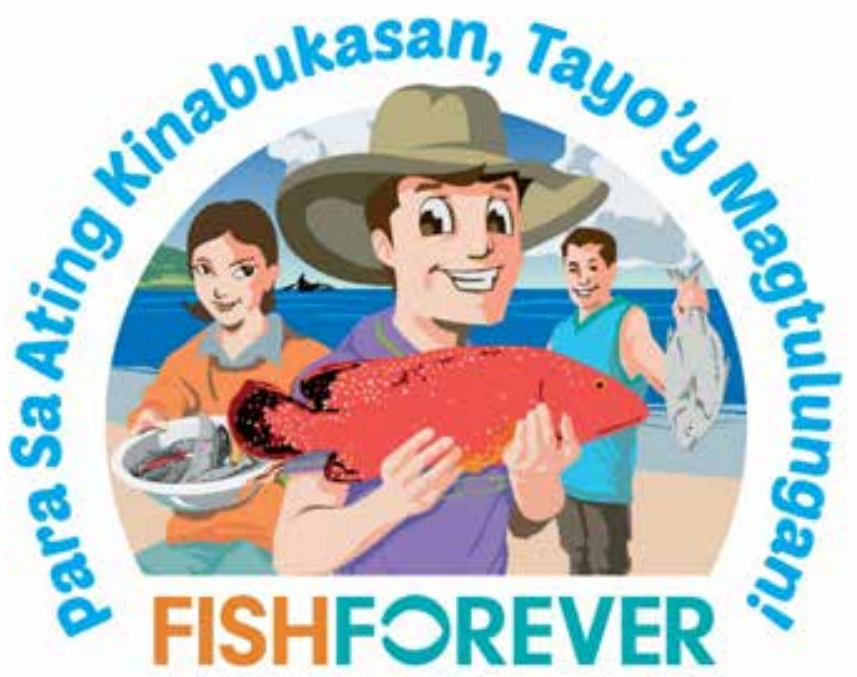

\section{Communication strategy}

Primary audience: Coastal fishers and municipalities

Location: Worldwide

Objective: To inspire fishers, decision makers and other stakeholders to take pride in their culture and natural resources, and to adopt practices and policies that conserve these resources.

Message: "Fish Forever" is the key message that ties all campaigns together, whether explicitly as in the Philippines' country brand or implicitly as in Brazil's country slogan: Fish, Conserve, Prosper.

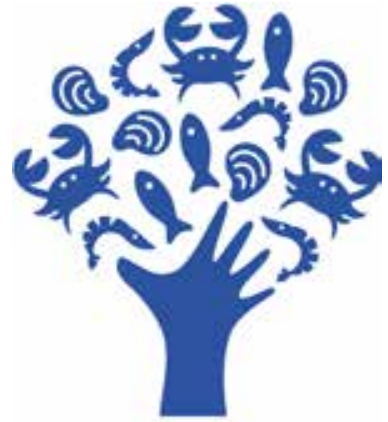

\section{PESCAR CONSERVAR PROSPERAR}

Rare trains and mentors local partner organizations to identify target audiences and understand the incentives and barriers to sustainable behaviour. This information is used to inform comprehensive campaigns - which Rare calls Pride Campaigns - that inspire communities and municipalities to take pride in their culture and natural resources in order to garner support for conservation. These campaigns employ a social marketing approach, which takes techniques from commercial marketing to change behaviour in order to achieve a particular social goal. For example, all Pride Campaigns include a human-sized mascot based on a local charismatic species, and events and materials - logos, billboards, calendars, posters, videos, radio programmes - are designed to appeal to multiple target audiences. The organization has conducted more than 400 Pride Campaigns in over 50 countries. Studies show they are effective in changing behaviour both in the short and long term. 


\section{Connecting with the audience}

Rare's Pride Campaigns in coastal fisheries fall under a specific Rare programme called Fish Forever, which combines Pride Campaigns with the planning and governance of regional networks of marine protected areas, rights-based fishery management and other science-based strategies to address overfishing. The campaigns' primary target audience is coastal communities. Fishers, households, leaders, decision makers, buyers and consumers are targeted through a variety of tactics based on behavioural insights. The implicit message is: "You are part of a group that has an important role to play in your

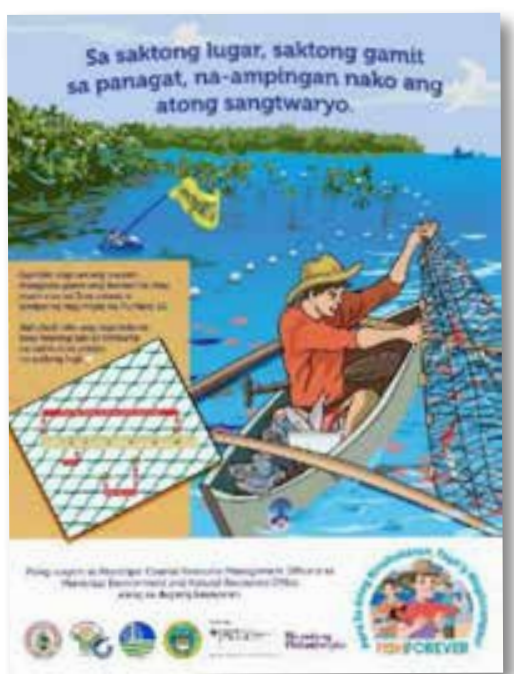
community, and you should be proud of that role. You also have the power to make changes in how you do things to make a difference for your community."

In the Philippines, for example, Rare and its partners are conducting several campaigns to reform small-scale coastal fisheries. In some cases, fishing is not necessarily viewed as a profession or even as a particularly admirable thing to do. Therefore, to instil pride among fishers, Rare is including the word profi (meaning both "professional fisher" and "professor") in its Filipino campaigns and giving out profi awards, based on fishers and community members nominating those who exemplify principles of sustainable fishing and act as "professors" of fishing. Recipients are publicly recognized, with these awards celebrating the positive behaviour that Rare and its partners are working to promote.

In parallel, networks of mayors in neighbouring municipalities are formed to promote dialogue, collaboration and commitment to regional marine planning and management. From these networks, political champions for sustainable coastal management emerge, who enhance advocacy for policy changes in favour of sustainable practices.

The development of each Rare campaign is guided by the organization's internal goals, such as its Theory of Change. Starting with the conservation results they want, planners then work backwards to identify stakeholders, current behaviours, barriers, and local context and values. Based on these insights, Pride Campaigns design engaging, relevant materials and events to deliver messages on resource management, often using 'entertainment-education' resources such as puppet shows and radio soap operas. In Palau in the mid-2000s, a Rare radio drama on coastal issues had a listenership of 40 per cent of the country's population. Rare is producing fewer radio shows now due to the proliferation of other media, including on the target audiences' cell phones. Nevertheless, many of the principles for making effective radio shows can also be applied to media sites such as YouTube, where Rare has posted hundreds of videos. For a current example of a marineoriented radio drama produced by other organizations, see the box on Punta Fuego below.

\section{Resources and timescales}

Rare's annual global budget is US\$25 million. The first Fish Forever Pride Campaigns costs ranged from US\$100,000 to US\$ 400,000 over three years. Currently, Rare is designing a modular approach to capacity-building that will enable local partners to adapt and implement Pride Campaigns in shorter time frames, allowing for resource efficiencies per person engaged. The Fish Forever programme is consolidating products and partnerships in three core areas: Community Engagement, Policy and Governance and Sustainable Finance to engage stakeholders at the local, regional and national levels. These range from a scientific reserve design team and a collaborative global data management system to blended finance mechanisms. These new systems and services allow Pride Campaign teams to focus on ensuring lasting behaviour change by developing trust with communities and local leaders, using and communicating science effectively, establishing inclusive and representative governance systems and strengthening natural resource management capacity. Additionally, Rare also recently launched a Center for Behavior \& the Environment, which partners with academic and research institutions to translate behavioural science into practical conservation solutions for internal and external projects.

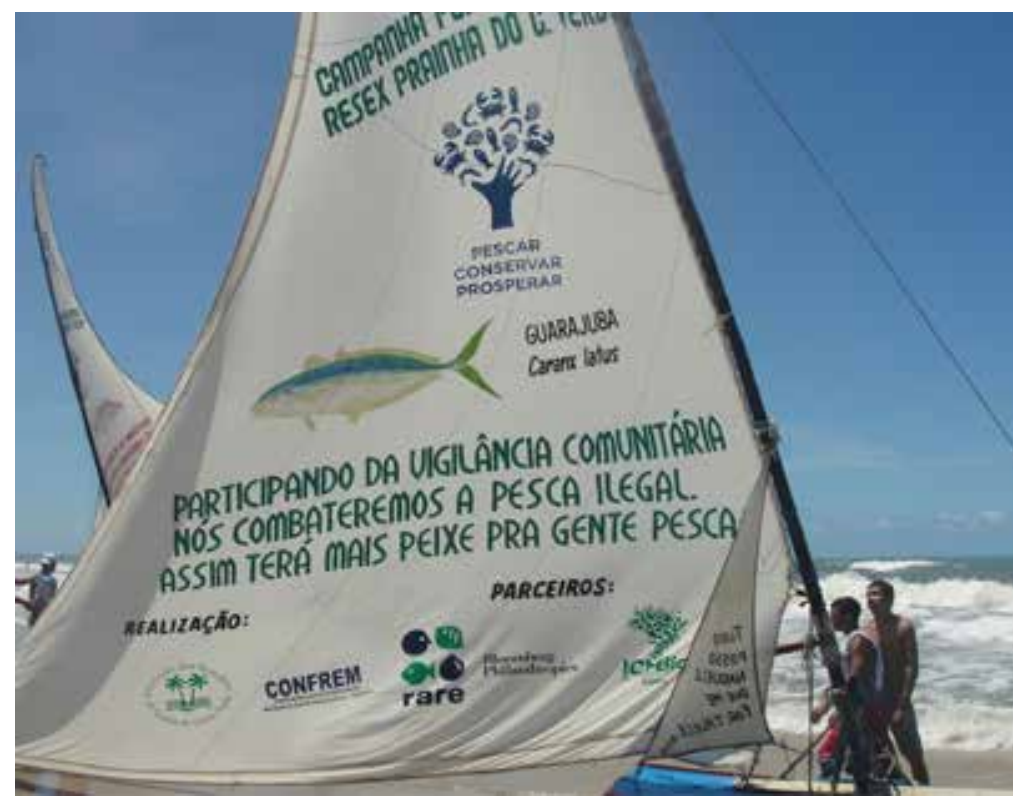

\section{Measuring success}

A recent meta-analysis of 84 Pride Campaigns indicated an 18 per cent increase on average in targeted behaviour adoption above baseline levels, within just a 12- to 16-month time frame. In other words, if 50 per cent of a population of fishers is already complying with no-take reserves, a Pride Campaign would increase compliance to 59 per cent on average within a year or so. In similar campaigns within the public health field, increases in behaviour adoption have averaged about half that level in similar time frames. Rare's recent three-year review of its Fish Forever programme included data from 15,000 household surveys in its programme areas and counted 650,000 fish at reef sites. 


\section{Connecting with the audience}

CCEF has two main target audiences:

- Local government staff: mayors and its legislatures (city/ municipal councillors), technical fisheries advisers, landuse planners, barangay captains (village chiefs) and its legislatures (barangay councillors)

- Stakeholders in local fishing communities: fishers and others who depend on marine resources for food and livelihood

A secondary audience is provincial government staff, since provinces in the Philippines have some influence on local governments and can provide resources to support conservation work. Increasingly, tourism operators are also an audience for CCEF, as the growing number of MPAs in the region has attracted more visitors. In the organization's early years, the need for marine conservation and the value of marine resources were the key messages for both main target audiences. However, with time the messaging for the target audiences diverged. As municipal governments have developed greater familiarity with marine resource management, they have required more technical guidance. For example, government staff expressed interest in designing an MPA, but required further information on setting boundaries for the area, selecting what habitats to include, etc. To support this, CCEF conducted ecosystem surveys and delivered the findings to government officials. For the wider communities, the messaging remains more general and is presented in various formats. CCEF has created posters, comic strips, videos, theatre productions and interactive games, among others, to communicate the need for better resource management, using local languages for these materials as much as possible (over 100 languages are spoken in the Philippines) to ensure their accessibility. The organization now also uses Facebook extensively as a communication tool. In its community work, CCEF identifies local champions for resource management (individuals willing to take the lead in working with peers and friends) and tailors its work to these people. For example, if the champion is an aspiring young scientist, CCEF will teach them how to carry out marine surveys and scuba dive. The goal is to help champions improve themselves and contribute back to the community. CCEF works with communities that want to see change and is mindful of their local politics, which can shift over time and potentially impact project success. For example, mayors may abandon projects if they believe the organization has worked too closely with particular mayors previously. For that reason, CCEF focuses on building long-term relationships with community champions, rather than working too closely with politicians. Despite this, politicians have generally been supportive of improving conservation and management of coastal resources, given the increasing awareness of how people and local economies depend on them.

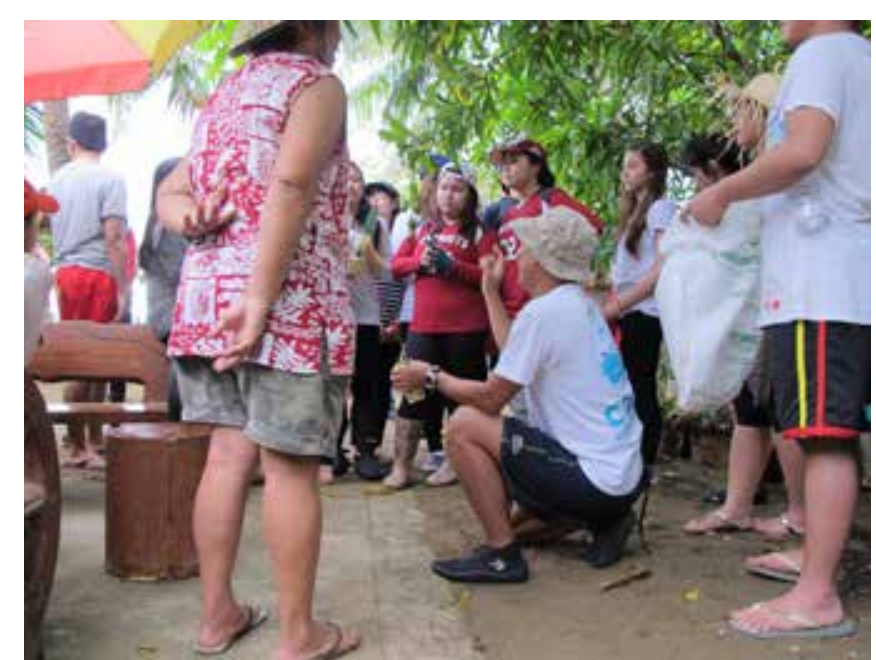

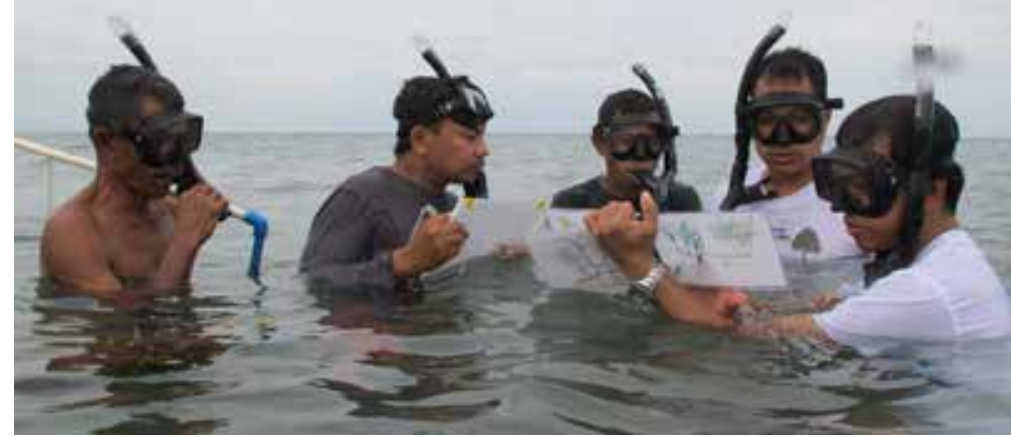

\section{Resources and timescales}

The CCEF budget is largely grant-based and has fluctuated over the years. Currently, the budget is a few hundred thousand dollars a year and covers work in roughly 10 municipalities and 15-20 communities, which varies depending on the level of funding. CCEF has worked in more than 100 communities over the years. Communication costs - namely salaries for communication staff and various operating expenses, such as printing - account for around 20 per cent of the budget. CCEF builds communications expenses into all its grants. The organization has two full-time communications staff. When hiring for these positions, CCEF looks for individuals who can write and speak well and who are self-motivated and sociable, since staff sent into communities are required to work and socialize with local stakeholders and speak intelligently about the organization's work. Communications staff also need experience with social media and visual media, which are becoming increasingly important for CCEF, who rely on community members to see and share photos and information of community meetings via Facebook, for example. CCEF staff have also produced short videos starring local community members on issues relating to MPAs or fisheries management, sometimes with humorous storylines showing someone causing trouble for their community and how the community responds to it, which are also posted on the organization's Facebook page.

\section{Measuring success}

When CCEF gauges the success of its communications, it measures not just changes in awareness and attitude - which it does through conducting before and after interviews with stakeholders - but also the impact on the marine environment. Typically, a coastal community in the Philippines ranges from 50 to 500 people and the critical mass for a local intervention, such as a small no-take MPA, is between 50 and 100 persons, who engage, assist and support the work depending on the size of the community. At least 10 per cent of the community must be fully on-board and engaged to move forward. In some cases, monitoring has continued for many years, though it can become less regular with time. CCEF has found that monitoring helps the community remain engaged and depending on the results can either stimulate their interest in continuing the work or trigger renewed or new leadership to reinvigorate it. How many MPAs have been designated following CCEF involvement? How has MPA designation impacted fish biomass? What is the coral cover? Nearly 100 community-based MPAs have been designated following the involvement of CCEF. Fish biomass in some MPAs - particularly where enforcement is adequate - has increased dramatically. Apo Island, a CCEF-linked MPA and one of the most studied in the Philippines, experienced a 50 per cent increase in fish biomass within two years of designation, which has continued to increase over time. 


\section{CASE STUDY \#5 | $\begin{aligned} & \text { Partnerships in Environmental } \\ & \text { Management for the Seas of }\end{aligned}$ East Asia (PEMSEA)}

https://url.grida.no/EBMCase5

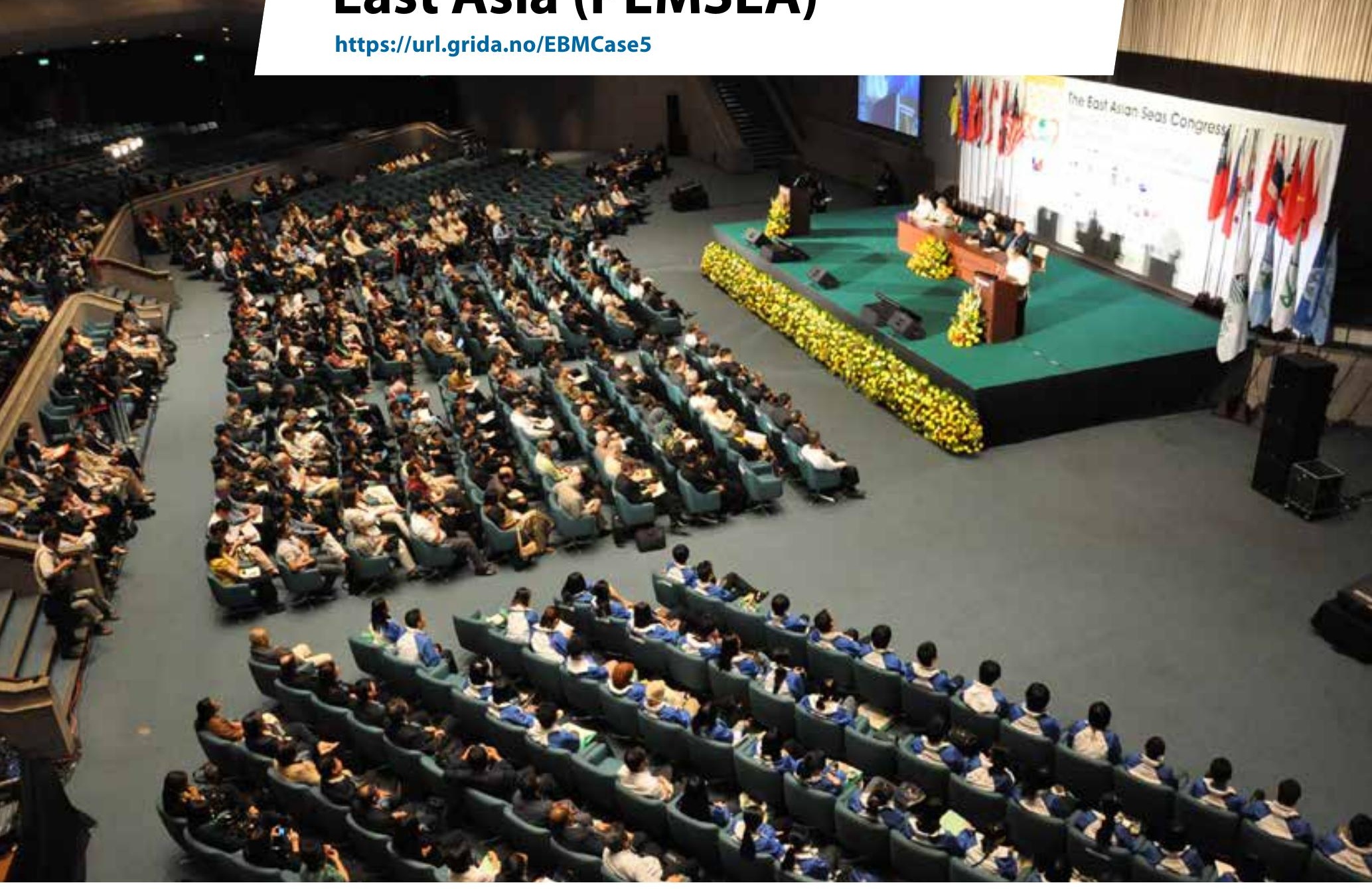

\section{Background}

The regional intergovernmental organization PEMSEA (Partnerships in Environmental Management for the Seas of East Asia) focuses on healthy oceans, people and economies and believes that ecosystem health and social well-being are central to economic progress. The organization's work involves spreading this message to enable real change for oceans and coasts, particularly by guiding East Asian governments to implement integrated coastal management. PEMSEA launched in 1993 as a Global Environment Facility (GEF) funded project, implemented by the United Nations Development Programme (UNDP) and executed by the International Maritime Organization (IMO), to coordinate East Asian efforts on marine pollution. By 1999, its focus broadened to encompass integrated coastal management. Four years later, partner governments* endorsed the Sustainable Development Strategy for the Seas of East Asia (SDS-SEA), outlining a shared vision for sustainable coastal development. The SDS-SEA was updated in 2015 to include a new target that aims for integrated coastal management to cover 25 per cent of the region's coastlines by 2021 .

*The country partners of PEMSEA are Cambodia, China, Indonesia, Japan, Laos, North Korea, the Philippines, South Korea, Singapore, Timor-Leste and Vietnam.

\section{Communication strategy}

Primary audience: Local and national government partners in the region

Location: East Asia

Objective: For diverse sectors to work collaboratively to ensure the sustainability of coastal areas. In contrast, single-sector management often fails to consider the various impacts of multiple uses of coastal resources.

Message: Communicating integrated coastal management is an iterative process that evolves over time based on what the intended audience needs.

As PEMSEA's responsibilities have broadened over time - including supporting governments to reach the 25 per cent target - so have its communication efforts. PEMSEA has earned a reputation in the global marine community as a model for producing science-based best practices for designing and implementing integrated coastal management by way of technical guidance: reports, manuals, books, brochures, policy briefs, webinars, case studies, conferences, certification services and more. To address its evolving needs and opportunities, the PEMSEA Resource Facility (PRF) - the communications arm of PEMSEA, which is part of its secretariat - continually adapts its communications strategy. 


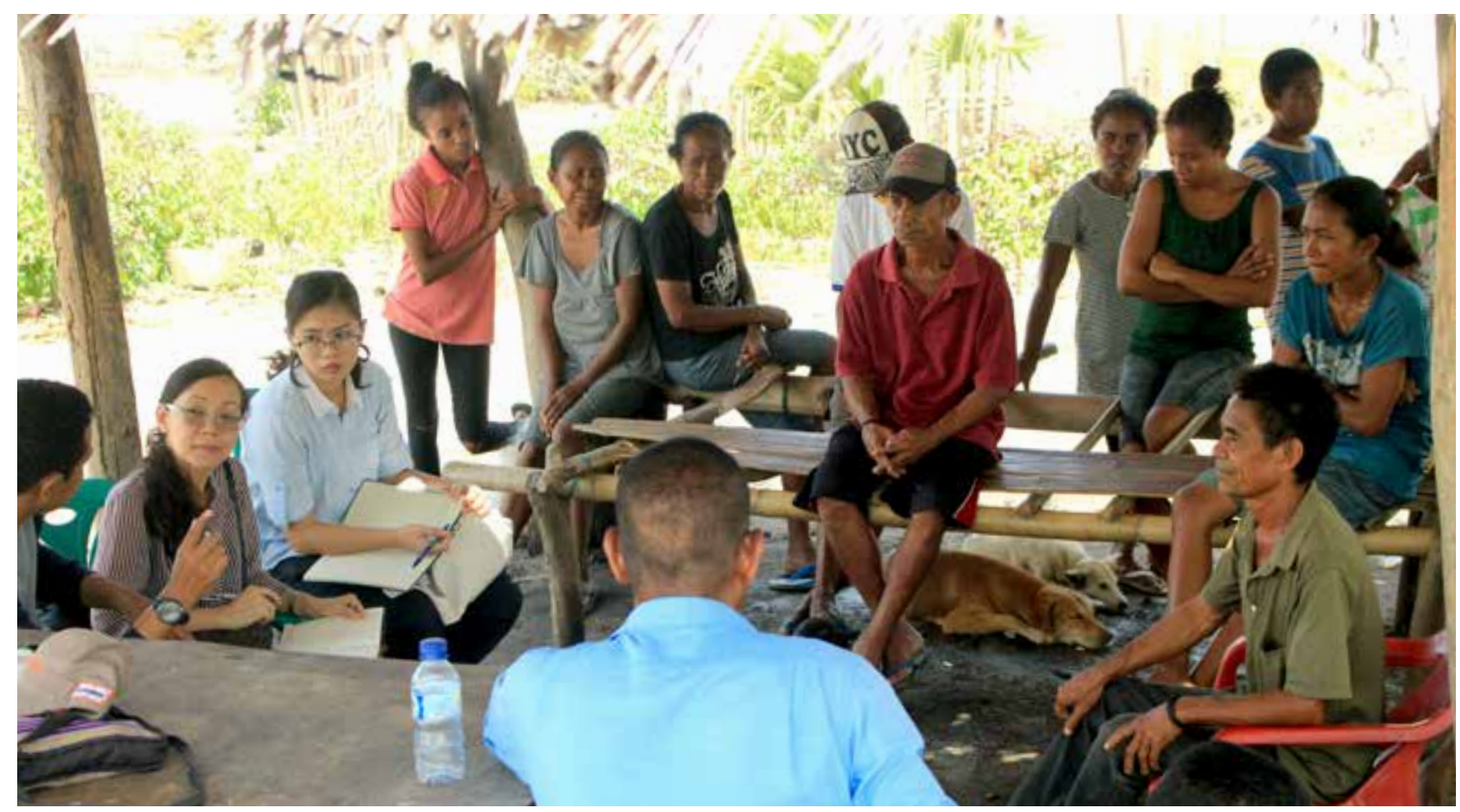

\section{Connecting with the audience}

PEMSEA's main audience is local and national government partners in the region, responsible for implementing integrated coastal management. PRF provides governments with customized services, including skills training, study tours, research and legal guidance. Case studies - providing examples for governments to replicate - are invaluable. PEMSEA has produced more than 50 in-depth cases of East Asian integrated coastal management implementation. PEMSEA's secondary audiences include international development organizations, research and science organizations, companies and potential investors. The East Asian region is a global maritime hub: eight of the world's top fifteen fish-producing countries are in East Asia, as are nine of the ten busiest container ports. When PEMSEA communicates with business audiences, it increasingly does so in the "blue economy" context, making a business case for investing in healthy ecosystems and discussing corporate return on investment. In 2015, PEMSEA worked with a consultant to re-examine its communication goals and identified a gap: although there were people in the region familiar with PEMSEA and had high opinions of its work, many institutions, including industry, had no knowledge of the organization or its services at all. To address this gap, PEMSEA now communicates about the organization and its work, as well as integrated coastal management. As part of its communications, it is also integrating a marketing approach, explaining its services and why it is a hub of expertise on coastal governance and the blue economy. Through this approach, PEMSEA seeks to attract and engage new partners, including the private sector.

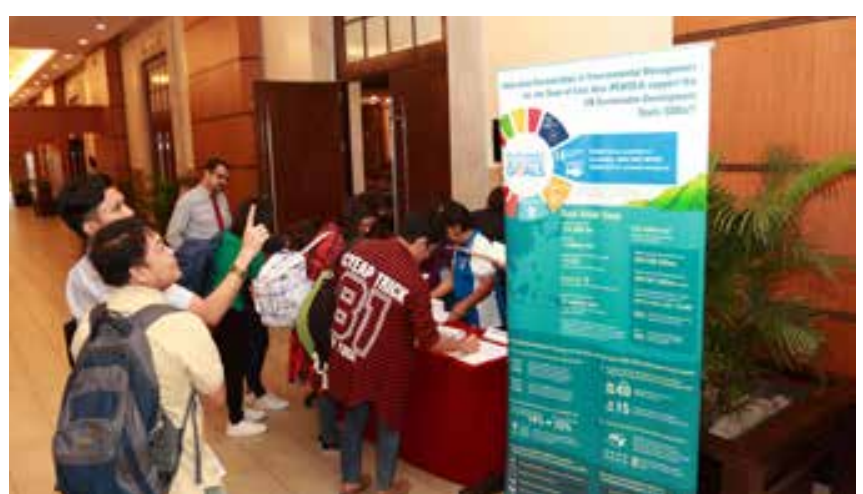

\section{Resources and timescales}

The annual budget for PRF is US\$ $2-3$ million. Communicationrelated actions are included in various budget areas and total around US\$100,000, which is roughly 4-5 per cent of the annual budget. Due to PEMSEA's emphasis on sciencebased technical guidance, the organization needs good communicators who also understand integrated coastal management and science, which is not a common skill set. PRF addresses this by employing in-house technical writers and an external, part-time communications consultant to guide the team. The use of social media and storytelling as communication techniques is still fairly new to PEMSEA, though the organization aims to grow these areas. The organization's expanding library of integrated coastal management case studies represents an entry point to such storytelling. PRF adapts its communications strategy annually, which involves updating an editorial calendar to identify emerging topics requiring communications materials the following year. PEMSEA also operates the Seas of East Asia Knowledge Bank, an online platform that allows data, experience and knowledge to be shared among policymakers, investors and other stakeholders.

\section{Measuring success}

PRF collects various data on its communication efforts: event attendance, web analytics, e-mail open rates, website visitors, social media followers and subscribers, among others. Measuring the success of communications efforts on regional progress towards the 25 per cent integrated coastal management coverage target by 2021 is less direct. As at March 2018, coverage stands at 20 per cent. While it is difficult to link this coverage to the organization's messaging or communications, it should be noted that the figure includes dozens of sites across East Asia where PRF personnel are directly involved in integrated coastal management projects or are advising them. In total, PEMSEA-country integrated coastal management projects impact more than $42,000 \mathrm{~km}$ of coastline. 


\section{Thinking out | Punta of the box Fuego}

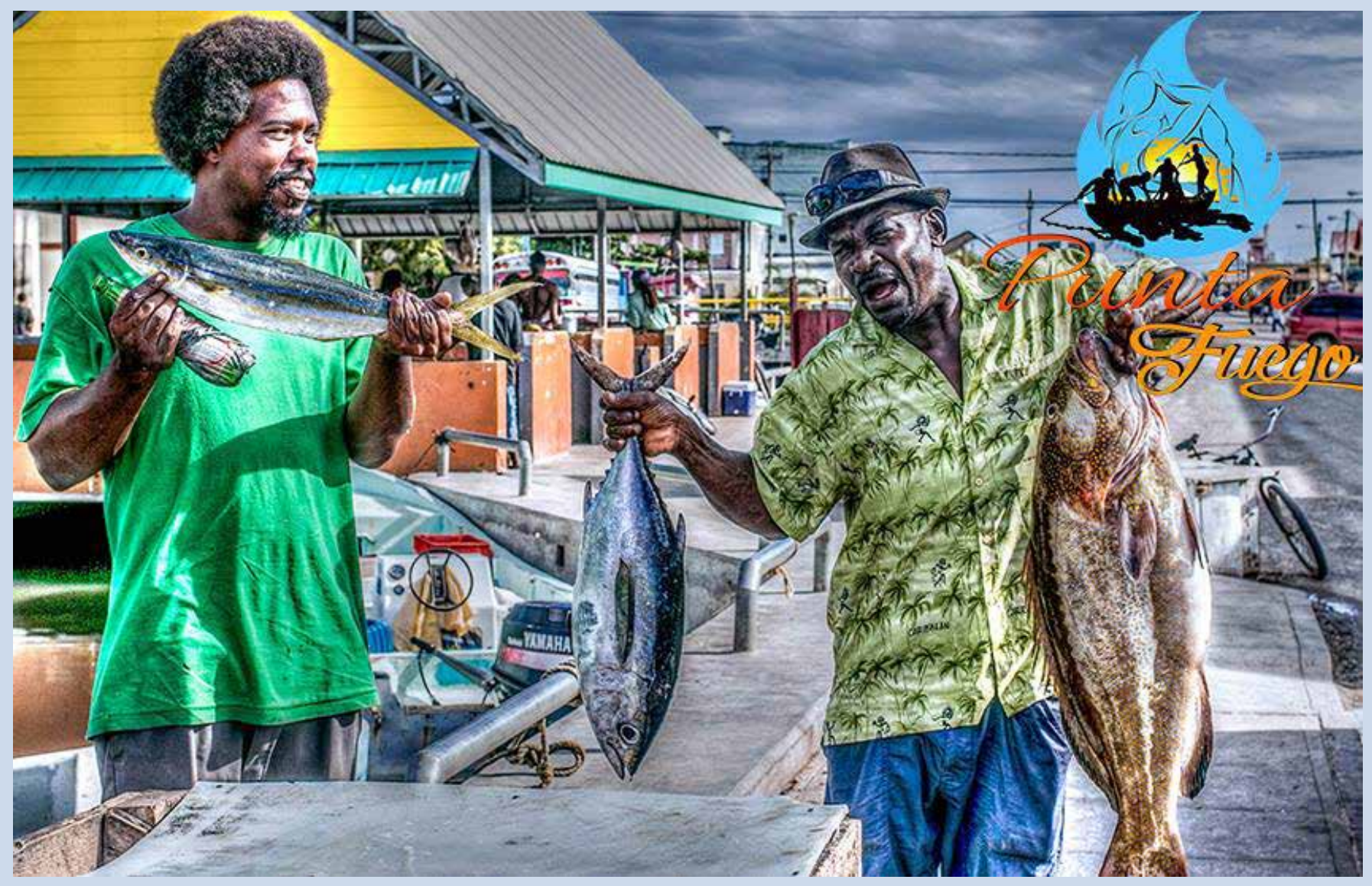

Primary audience: Small-scale fishers

Location: Belize

Objective: To change fishers' attitudes and behaviour to encourage responsible fishing and respect of MPAs.

Message: Through combining entertainment and education, communications on ecosystem-based management can engage stakeholders and improve their knowledge of marine management.

Wildlife Conservation Society Belize (WCS) and PCI Media Impact are co-producing a hit radio drama in Belize called Punta Fuego. The weekly show aims to change small-scale fishers' attitudes and behaviour to encourage responsible fishing and respect for MPAs in Belize. It communicates this through a fast-paced plotline that has romance, injustice, corruption, and more, all centred on the fictional coastal fishing village of Punta Fuego. WCS and PCI Media Impact supplement the radio drama with other communication methods. Following each Punta Fuego broadcast is a call-in show on fishing issues (Talking Fuego). In addition, Punta Fuego cast members visit coastal villages in Belize and a new annual award - the Punta Fuego Fisher of the Year Award - has been created for local fishers who practice sustainable fishing. WCS coordinates with other NGOs in Belize to integrate Punta Fuego messaging into their communications. There is strong evidence that slightly more than half of all fishers in Belize had listened to Punta Fuego by the end of 2016, that listeners believed the quality of the programme had improved substantially between seasons one and two, and that more fishers became regular listeners during season two.
Furthermore, most listeners also listened to its associated talk programme. Those who listened were more likely to possess accurate knowledge of Belize's fisheries regulations, recognize the benefits of MPAs, and share their knowledge with other fishers. In the evaluation, one fisher who had listened to the programme said, "Finally someone is talking to us, speaking to our issues."

WCS and PCI Media Impact hired an experienced Belizean writer and voice actors, and built a professional recording studio at the WCS offices. The Punta Fuego project "mapped" characters so that each would influence the target audience differently, and pretest shows were held for the intended audience to assess the effectiveness of this mapping. The budget for season one of Punta Fuego was $\$ 125,000$.

The show represents a new direction for both WCS and PCI Media Impact. WCS is historically a research and monitoring organization, and Punta Fuego was the Belize office's first major communication initiative. For PCI Media Impact, which is staffed with several former Rare employees and has produced over 100 serial radio and television programmes on social issues (primarily family planning), Punta Fuego was one of its first coastal/marine focused programmes.

"Now that we're planning for season three of Punta Fuego," says Alleyne Regis, Caribbean Program Manager of PCI Media Impact, "to know that a science organization like WCS sees the value of something like this speaks volumes." 


\section{Sharing is caring: lessons learned from the case studies}

A "lessons learned" or "continuous improvement" process should be an instrumental part of any project, since identifying and learning from mistakes and successes can help future projects cross functional boundaries and save time and money. Following such a process involves two essential activities: capturing important lessons learned and making effective use of these. To capture lessons learned, case study holders were asked to share their experiences, specifically detailing where they succeeded and what they would recommend for other projects with similar activities.

\section{Abu Dhabi Blue Carbon Demonstration Project}

The key success factor for this project was good planning, which combined scientific expertise with thorough local knowledge of target audiences. "There is so much local cultural knowledge and experience that you need to know to do a project like this," says Christian Neumann of GRID-Arendal. Jane Glavan of AGEDI explains that "the systematic approach and depth are where we got our success. That success has led me to advocate for similar communication efforts in AGEDI projects moving forward." In this case, an in-depth systematic approach to planning led to the effective communication on the value of blue carbon, which has now been integrated into multiple policies as a result. "Blue carbon is very much a part of the language now in Abu Dhabi; our communication efforts helped mainstream blue carbon from a technical, scientific, misunderstood term," says Glavan.

\section{Marine Plan Partnership (MaPP) for the North Pacific Coast of British Columbia, Canada}

MaPP used its communications to educate stakeholders on complex ecosystem-based management issues. Storytelling was an invaluable method, favouring simple and meaningful messaging over technical jargon to show how ecosystem-based management related to stakeholders. Robust funding support also meant that MaPP was able to hire the necessary communications staff and consultants. "Budget for your communications right away. Don't underestimate the need for education-based communications. It pays to get good people," notes Charlie Short, who led MaPP planning for the British Columbia Government. The stories provided snapshots of issues, profiled stakeholders and explained complex activities, such as cumulative effects through everyday examples. To engage its target audiences, MaPP showed it was dedicated to respecting and integrating their input, even though the input was officially advisory. This involved dozens of advisory committee meetings, open houses and other in-person discussions over the years, including field trips by industry representatives to First Nations communities. "Just offering information by itself doesn't create interest and interaction," says Steve Diggon, MaPP planning coordinator for the Coastal First Nations alliance. "Stakeholders need to know they're having meaningful input. That takes trust, which must be built."

\section{Rare and its Pride Campaigns}

Changing human behaviour can seem daunting, as people are most comfortable with the status quo. To effect such change, practitioners must understand why people behave the way they do, including values and norms, as well as the barriers that exist around certain behaviours. "You almost don't have to be an expert on anything - you just need to be able to empathize," says Kevin Green, Senior Director of Rare's Center for Behavior $\&$ the Environment. In their Pride Campaigns, Rare uses emotional appeals to inspire people to change their behavior, social incentives to create positive reinforcement to adopt new behaviours permanently, and specific architecture to create a supportive decision-making environment for sustainable behaviours. Rare seeks to incorporate the newest research into its models, while working to simplify its approach, presenting its concepts in language accessible to local partners. Rather than leave behavioural science-related work to the experts, Rare believes that everyone can use it as a powerful tool for conversation. "We can't rely on the science itself to translate easily to practitioners," says Green. The ultimate lesson is that communication is all about empathy. "If we can develop a sophisticated and genuine empathy for the audiences we're working with and designing for, that's probably the most important part. And we're always working to get better and better at that."

\section{Coastal Conservation and Education Foundation (CCEF), the Philippines}

Communicating the need for ecosystem-based management often means building appreciation for marine conservation from the ground up. "Marine conservation is not a universal body of knowledge," says Alan White, President of the CCEF Board of Trustees. CCEF conducts before and after surveys on stakeholder awareness, as well as before and after field surveys on fish counts and ecosystem conditions, to give their communications scientific impact, which are carried out with vigour. "We can actually show scientifically and objectively that our work has made a difference". The marine surveys tell the story of how well managed the sites are and almost always show improved or stable biomass and healthier coral reef. Such monitoring is important to reinforce the community's work. "It all has to do with improving awareness about managing marine resources, and what people lose when they don't do that." One key to success has been "learning by doing", through trying new approaches, seeing what works and adapting to changing conditions. Successes and failures are captured in project reports, reports to donors, project newsletters and annual reports. Communications require flexibility and CCEF therefore gives its communications staff the freedom to engage target audiences in creative ways. "As a small organization with limited time, budget and people, you need to figure out where you can be most effective," says White. "You need to be sensitive to their interests, needs and biases. Figure out where you're going to be most effective with the resources you have." The personalities of staff and their ability to socialize with audiences are crucial for successful communications, though CCEF recognizes the limits to how much it can do. Some local mayors or communities are resistant to the organization's messaging, and in these cases, it is best not to keep pushing messages towards them. "There has to be demand. Otherwise you're better off staying away." 


\section{Partnerships in Environmental Management for the Seas of East Asia (PEMSEA)}

PEMSEA has 25 years of producing science-based technical guidance on integrated coastal management, which serves the organization well. "One of the challenges of PEMSEA is to describe it to a layperson. Part of what we've done in the past few years is to think hard about what we want our communications to accomplish." says Ryan Whisnant, Director of Strategic Initiatives at the PEMSEA Resource Facility (PRF). Although the organization is increasingly aware of the need to market itself as well as educate audiences, science still comes first. "The focus on being science-based is key," notes Aimee Gonzales, Executive Director of PRF. As evidenced by PEMSEA's communications rebranding in 2015 and annual adaptation of its communications strategy, the organization views communication as a continually evolving process. PEMSEA is looking to source more local stories, for example, to better explain how integrated coastal management is relevant to people's lives. "PEMSEA is known for all the great technical documentation it puts out. But we're now looking also to put out non-technical information - describing integrated coastal management in plain language," says Whisnant. As an international organization, PEMSEA has benefits that other institutions, such as NGOs, in the region may not, including access to partner governments. This is greatly facilitated by PRF, which serves as the coordinating body for PEMSEA and helps countries implement integrated coastal management, with communications being an integral part of this work. 


\section{Applying best practices to your practice: five things to adopt}

\section{Keep the message simple, but with a strong meaning}

Simple and inspiring messages that are relatable and easy to understand should be at the core of all of your communications. Facts and figures will not be remembered alone and should be integrated into specific messages, as a way to help stakeholders connect their efforts to a project's objectives. Authentic messages will help your stakeholders see challenges and opportunities as you see them, and understand and care about the project's direction. Help your audience understand the relevance of your strategy with real-life examples, using these to spark a dialogue that fosters greater understanding of the behaviours that you want to encourage against those that pose risks.

\section{Use twenty-first-century media and be (un)expected}

The way people communicate has changed tremendously in recent years. The way that messages are delivered is as important as the content itself. Consider using social media, networking, blogs and other modern media to spread your messages in ways that are familiar to your stakeholders. Where you display your messages is also important. Connect with your stakeholders and audiences, get to know their daily activities and try to catch them somewhere they would either most or least expect.

\section{Build an effective feedback loop}

Develop a strong feedback loop so you can receive information on whether your communication plan and messages are working and quickly adjust these if not. Setting up an online forum or creating feedback forms are easy ways to gather information and will help you fine tine your communications to ensure that your messages are aligned with your stakeholders' interests and attitudes.

\section{Promote the collective "action knowledge"}

People are more inclined to act if they know what they can do about a given problem and believe that their actions will help solve it. No individual is going to be able to make a lot of changes, but by working together, people can come up with share solutions. Your messaging strategy should aim to create attachment to community values, as this will help group's develop a sense of shared responsibility and build their confidence to act, which is fundamental for working towards a shared goal to enact change.

\section{Test, test, test}

Once you have developed your messages, it is time to test them out. Incorporate feedback from internal and external collaborators and ensure that they approve the final key messages. Over time, routinely revisit the key messages to ensure that they still meet your needs and those of the audience, and that they also reflect current trends, research and issues you are addressing. 


\section{Reference Material}

United Nations Environment Programme (UN Environment) (2011). Taking Steps toward Marine and Coastal Ecosystem-Based Management- An Introductory Guide. Available at: https://wedocs. unep.org/bitstream/handle/20.500.11822/13322/GLOCIEBM. pdf? sequence $=1$ \&isAllowed $=y$

\section{\#1 Abu Dhabi Blue Carbon Demonstration Project}

Communications Outreach and Capacity Building Plan Final.docx Development_of_publication_material_FINAL.doc

Final AD BC Stakeholder Engagement Plan.doc

\#2 Marine Planning Partnership (MaPP) for the North Pacific Coast of British Columbia, Canada

MaPP website: http://mappocean.org/

10 Things You Need to Know about MaPP (video): https://vimeo. com/88206954

Planning Canada's Pacific Coast: What Made it Work (Marine Ecosystems and Management article): https://meam.openchannels.org/news/ meam/planning-canada\%E2\%80\%99s-pacific-coast-what-made-itwork

\section{\#3 Rare and its Pride Campaigns}

Butler P., Green, K. and Galvin, D. (2013). The Principles of Pride: The science behind the mascots. Available at: https://www.rare.org/sites/default/files/ Principles\%2520of\%2520Pride\%25202013\%2520lo\%2520res.pdf

Vaughan, P., Regis, A. and St. Catherine, E. (2000). “Effects of an Entertainment-Education Radio Soap Opera on Family Planning And HIV Prevention in St. Lucia". International Family Planning Perspective, Vol. 26, No. 4. Available at: https://www.guttmacher.org/ sites/default/files/pdfs/pubs/journals/2614800.pdf

\#4 Coastal Conservation and Education Foundation (CCEF), Philippines

CCEF. "Getting involved with MPAs... with Inday!" (comic strip sample): https://mpanews.openchannels.org/sites/default/files/mpanews/ CCEFposter.pdf

i-Dive - Responsible Diving in Marine Protected Areas (video): http:// coast.ph/?q=awhite-library/collection/i-dive-responsible-divingmarine-protected-areas
White, A. T., Vogt, H. and Arin, T. (2000). "Philippine Coral Reefs Under Threat: The Economic Losses Caused by Reef Destruction", Marine Pollution Bulletin, Vol. 40, No.7.

Walmsley, S. F. and White, A. T. (2003). "Influence of social, management and enforcement factors on the long-term ecological effects of marine sanctuaries", Environmental Conservation, Vol. 30, No. 4, pp. 388-407.

Eisma-Osorio, R-L. et al. (2009). "Scaling Up Local Government Initiatives Toward Ecosystem-Based Fisheries Management in Southeast Cebu Island, Philippines", Coastal Management, pp. 291-307.

White, A. T., Ross, M. A. and Flores, M. (2009)."Benefits and Costs of Coral Reef and Wetland Management, Olango Island, Philippines", manuscript.

Varney A. et al. (2010). Designing and Planning a Network of Community-Based Marine Protected Areas, CCEF.

Maypa, A. P. et al. (2012). "Marine Protected Area Management Effectiveness: Progress and Lessons in the Philippines", Coastal Management, pp. 510-524.

\#5 Partnerships in Environmental Management for the Seas of East Asia (PEMSEA)

Case studies on ICM implementation: http://pemsea.org/publications/ case-studies

Integrated Coastal Management Code (2015): http://pemsea.org/sites/ default/files/ICM\%20Code\%202015\%20-\%20BLUE\%20\%28Aug\%20 25\%202016\%29\%20-\%201.pdf

Sustainable Development Strategy for the Seas of East Asia (2015): http://pemsea.org/sites/default/files/SDS-SEA\%202015\%20 FINAL\%2011272015\%20FULL\%20rev_1.pdf

Perspectives on Building a Regional Mechanism for Coastal and Ocean Governance in the Seas of East Asia (2013): http://pemsea.org/ publications/perspectives-building-regional-mechanism-coastaland-ocean-governance-seas-east-asia

\section{Thinking out of the box: Punta Fuego}

PCI Media Impact web page on Punta Fuego: https://www.pcimedia. org/environment

Punta Fuego Facebook page: https://www.facebook.com/ puntafuegobelize/videos/1334705219875417/

WCS (2015). “Punta Fuego Celebrates a Successful First Season as Belize's Hottest Radio Drama": https://newsroom.wcs.org/News-Releases/ articleType/ArticleView/articleld/8394/Punta-Fuego-Celebrates-aSuccessful-First-Season-as-Belizes-Hottest-Radio-Drama.aspx 


\section{Photo Credits}

Cover Rob Barnes, GRID-Arendal under license from AGEDI

Rob Barnes, GRID-Arendal under license from AGEDI

Megan Dickinson, Marine Plan Partnership (MaPP)

Rare

Michelle Baird, Coastal Conservation and Education Foundation (CCEF)

Partnerships in Environmental Management for the Seas of East Asia (PEMSEA)

Maria Potouroglou, GRID-Arendal

7-8 Rob Barnes, GRID-Arendal under license from AGEDI

8 AGEDI/ Riccardo Pravettoni, GRID-Arendal

9 Rob Barnes, GRID-Arendal under license from AGEDI

10 Megan Dickinson, Marine Plan Partnership (MaPP)

10 Gilian Dusting, Marine Plan Partnership (MaPP)

11 Megan Dickinson, Marine Plan Partnership (MaPP)

11 Jillian Tamblyn, Marine Plan Partnership (MaPP)

11 Steve Diggon, Marine Plan Partnership (MaPP)

12-13 Rare

14 Michelle Baird, Coastal Conservation and Education Foundation (CCEF)

15 Coastal Conservation and Education Foundation (CCEF)

16-17 Partnerships in Environmental Management for the Seas of East Asia (PEMSEA)

$\mathrm{PCI}$ Media Impact Staff 
Communication, originating from the Latin word communis meaning "common", should be the glue that binds all ecosystem-based management stakeholders and processes. This report contains information on good practices, as well as providing some guidelines on how to design a communication plan that is tailored to your project by considering the following aspects: developing your communication strategy, connecting with your audience, resources and timescales, measuring success and lessons learned.

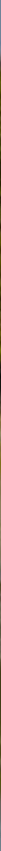

